times to pace to and fro, always, however, keeping the eyes directed towards the firmament in quest of meteors."

Our medallist has recently published in the Observatory an instructive and opportune series of papers on the great showers of Leonids which may reasonably be expected in the next year or two. This subject is here discussed with characteristic wealth of knowledge and experience. He commences with the remark: "It may be safely said that in the month of November during the next few years, all astronomers and a large majority of the general public will becrme meteoric observers, for the phenomena presented will be of an exceptional kind and of a character to interest every one."

We all echo these words. I think $\mathrm{I}$ am justified in adding that much of the recently awakened interest in the subject has been due to the worthy example Mr. Denning has himself given us. Which of us would not be proud to emulate his singlehearted and enthusiastic devotion to the discovery of truth in this beautiful department of astronomy?

It is a matter of great regret to every one here assembled that our medallist, whom we greatly wish to honour, is not now present to accept in person our award. We regret this all the more when we learn that ill-health is the cause of his absence. We all join in a hearty wish for his speedy recovery, and in the hope that he may shortly be able to resume those observations which we receive with such interest and pleasure. We desire to assure him not only of our appreciation of his admirable work, but of the high esteem which we entertain for the spirit in which that work has been conducted.

On your behalf, therefore, I now hand the Gold Medal of the Royal Astronomical Society to our Secretary, to be by him transmitted to Mr. W. F. Denning in recognition of the valuable services to our science he has rendered, especially in the department of meteoric astronomy.

\section{HISTORY AND OBJECTS OF THE PHYSICAL SOCIETY.}

I PROPOSE on this occasion to begin with a few words on the history and objects of our Society, and afterwards to glance briefly at the principal events of physical interest which have occurred during the past year.

The Physical Society was founded in 1874 , and owed its origin mainly to the initiative of the late Prof. Guthrie. From the first years of its existence up to the present time it has included among its members nearly all the leading physicists of the United Kingdom.

In the early days our meetings were, by permission of the Lords of the Committee of Council on Education, held in the Physics lecture-room of the Royal College of Science at three o'clock on Saturday afternoons, members being allowed the free use of the laboratory apparatus for the illustration of their papers. The proceedings were at that time rather less formal than is customary at present. The papers were rarely, if ever "referred" before being read; often, indeed, they were read long before they were actually written, while a large proportion of the communications were of a purely oral character, and never intended for publication at all, except perhaps in the short notes which the reporter sent to the scientific journals. Special prominence was given to experimental demonstrations illustrative not only of original researches, but also of such work carried on outside the Society as happened to be attracting attention at the time. . .

Under the somewhat lax régime which then prevailed, it necessarily happened that the communications made to the Society were not always of a very high order of merit. . . But from the very beginning the Council has always been carefu not to print in the Proceedings anything that was not of sound scientific value, and while the number of important papers that have been published through the medium of the Physical Society is large, very little of doubtful quality has found a place in the Journal.

The first material change in our routine took place in the year I889, when the day and hour of meeting were altered from Saturday afternoon at three to Friday at five o'clock. . . . I may here mention that the Council has more than once con sidered whether it might not be expedient to hold our meetings in the evening. Many, no doubt, would consider this prefer-

1 Presidential Address to the Physical Society. (Abstract.) February II By Shelford Bidwell, F.R.S. able, but the balance of convenience appears to be clearly in favour of the afternoon.

During the South Kensington epoch the Physical Society published ard presented to its members a number of valuable books, including, among others, Prof. Everett's well-known treatise on the C.G.S. system of units and the works of Wheatstone and of Joule. It also issued twelve volumes of Proceedings, in which were collected such of the communications to the Society as had been approved for publication. By an arrangement with the proprietors of the Philosophical Magazine the same papers were also (as now) printed in that journal, being thus, to the author's great advantage, assured of a wide circulation throughout the scientific world. In the same period, notwithstanding the small amount of the annual subscription paid by members and of the composition fee for life membership, the Society's income so far exceeded its expenditure that it was able to accu. mulate and invest a capital of nearly $3000 \%$

When the Society entered upon its twenty-first year with a position which, if somewhat unpretending, was well recognised and firmly established, it was felt that the time had come when, in the interests of physical science, something more than had been already achieved might fairly be demanded of it. British physicists had long been at a serious disadvantage in that they were without any means of readily ascertaining what was being done by their fellow-workers in other countries; with the multiplication of scientific literature the need of some periodical digest similar in character to the German Beiblätter was becom. ing year by year more urgent. To endeavour to meet this want was a duty which clearly devolved upon the Physical Society, and the Council anxiously considered the question whether the publication of monthly abstracts of physical papers appearing in foreign journals could be undertaken by ourselves.

The only serious objection to the enterprise was of a financial nature. The work, if it were to be carried out efficiently, would certainly necessitate an annual expenditure exceeding by some hundreds of pounds the total income of the Society. This could only be met by raising the amount of the annual subscrip. tion and composition fee, which, as I have mentioned, were un usually low. But it is a delicate and difficult matter to ask existing members of a society for increased subscriptions unless very excellent reasons can be shown for the demand. The Council therefore determined that they would publish a series of abstracts for one year at least before taking any steps to provide additional income, defraying the cost from cash in hand and, i need should arise, drawing upon the invested capital. In this way it was hoped to convince members of the utility of the undertaking which they were to be called upon to support.

I need not remind you of the highly satisfactory result of the experiment. The work of the able and assiduous body of abstractors whose names appear on the cover of our Proceedings was on all sides cordially approved, and at a special genera meeting, held in 1896 , a resolution submitted to the Society for increasing the subscription to two guineas per annum was passed almost, if not quite, unanimously. The number of those who in consequence of this increase have resigned their membership has been unexpectedly small, while on the other hand many of the life members have, in response to the invitation issued to them, voluntarily contributed an additional fifteen guineas to the funds of the Society, in recognition of the fact that they are now in enjoyment of greater and more costly advantages than were contemplated at the time when they paid their very moderate composition fees. To such as have not yet responded I venture to repeat the invitation.

Although the abstracts were actually published for two years before the increased subscriptions began to come in, the whole cost was met out of uninvested cash, supplemented by grants liberally made by the British Association and the Royal Society, and it was never found necessary to draw anything at all from the reserve fund. I wish to emphasise this fact because the abundant caution properly exercised by the Council in entering upon a new and uncertain enterprise appears to have led to a very general impression that the Society had outrun its means and was on the verge of bankruptcy, whereas in truth it was never in a more prosperous financial condition than it is at present.

On October 26, I 894 , the Society met for the first time in this room. Although the privileges so generously accorded to us by the authorities at South Kensington were highly valued, it was nevertheless deemed advisable that we should leave the home of our youth and seek a footing in Burlington House, the 
headquarters of scientific associations. Here the Chemical Society offered us a most kindly and cordial welcome, and provided us with a meeting-place which is not only more generally accessible than the old one, but is also on other grounds more convenient to most of our Fellows.

By this time the general affairs of the Society had assumed a more business-like condition. Amongst other things, greater care was exercised with regard to the acceptance of communications. I need hardly say that no paper is in these days allowed to be read unless it has been first referred to some competent authority and favourably reported on. The most distinguished physicists in the kingdom have given their services as referees, and our heartiest thanks are due to them for the care and patience which they have ungrudgingly bestowed upon a somewhat ungrateful task.

The practice was also introduced of putting the more im. portant papers into type before they were read, and distributing proofs among such of the Fellows as were known to be specially interested in the subjects to which they related. This course has led to a considerable improvement in the value of the discussions.

The most recent step in advance consists in the adoption of a scheme for greatly extending the list of journals from which the monthly abstracts are made. Hitherto the papers abstracted have been exclusively such as had been published in foreign journals, and were of primarily scientific interest. In the present year, as the result of an agreement with the Institution of Electrical Engineers, the number of the abstracts is to be largely increased, British publications and papers of a technical character being included in their scope. The arrangement in question is open to the objection that it entails the loss of our monopoly in the publication, for members of the Institution of Electrical Engineers will, like ourselves, receive copies of the abstracts, and will share with us whatever credit attaches to their production. The objection, however, appears to be in the main only a sentimental one, and of small weight in relation to the substantial advantage accruing to our members-an advantage which could not possibly have been provided out of our own unaided resources. [Reference was then made to the advantages afforded ly the Physical and other kindred Societies in promoting friendly intercourse among fellow-workers in a particular branch of science.]

Through the kindness of certain influential gentlemen belonging to the Society, we have from time to time been afforded the opportunity of holding a meeting in some well-known physical laboratory either in town or in the country. I myself have had the privilege of taking part in most agreeable pilgrimages to Oxford, Cambridge and Bristol, and have also heen among those who enjoyed the hospitality of Profs. Adams, Carey Foster, Ayrton and Thompson at their laboratories in London. I have pleasure in announcing that the Council bas accepted an invitation from our Fellow, Mr. Porter, to go to Eton for the next meeting on February 26, and I trust that our appreciation of his kindness will be testified by a large gathering. It is a little difficult to beg for favours, but I may be allowed to suggest to those who are in a position to exercise similar hospitality, that they have it in their power to contribute, in a material degree, and in more than a merely scientific sense, to the well-being of the Society.

[The second part of the address dealt with the discovery of the Zeeman effect ; some of the principal papers published by the Physical Society in 1897 ; the appointment of the National Physical Laboratory Committee, and the foundation of the Rontgen Society.]

\section{THE INSTITUTION OF MECHANICAL ENGINEERS.}

THE annual general meeting of the Institution of Mechanical Engineers was held in the theatre of the Institution of Civil Engineers on the evenings of the Ioth and IIth insts. The usual formal proceedings having been gone through, the retiring President-Mr. E. Windsor Richardsintroduced the new President, Mr. Samuel W. Johnson, who is locomotive superintendent to the Midland Railway. There were two papers down for discussion, and there was also an adjourned discussion on a paper entitled "Mechanical Features of Electric Traction," which had been read and partially discussed at the last meeting of the Institution. This paper was contributed by Mr. Philip Dawson, who is largely interested in the introduction of mechanical appliances in connection with electrical engineering into this country from America. Under these circumstances it was natural that the contribution should be of a general rather than a scientific character. The prominent feature in the paper was the fact that electrical traction has spread so rapidly in America, whilst very little has been done in this country. For instance, out of a total of nearly 15,030 miles of tramways in America in the year I895, I2, 583 miles are worked electrically. Cable traction, which was at one time so popular, and which seemed to have so promising a future before it, has been quite eclipsed by electrical methods, there being only 600 miles of rope tramway in the States in the same year. Steam has even a lower total, there being but 519 iniles. Horse traction supplies the balance of something over I 200 miles. Great Britain and the Colonies in the year 1896 had but 167 miles of electric tramway, thus being far below Germany, which had a total of 618 miles. The only other European country having more than Ioo miles was Austro-Hungary, with a total of I 20 miles. Belgium had 90 miles, France 67, Italy 50, and Switzerland and Russia 30 miles each ; whilst other European countries contribute 30 miles altngether.

It is not necessary we should follow the author in the practical details he gives regarding the various features of motors, trucks, cars, permanent way, contluctors, methods of transmission, generating stations, \&c. The long discussion on this paper resclved itself very largely into a controversy as to whether English engineers should follow American precedents. Prof. Unwin, in the speech that he made, entered a timely protest against the spirit of detraction which animated a good many of the speakers. As he said, American engineers may not be perfect in all their practice, and it is quite possible improvements may be made upon their methods, still they have had considerable experience, and what they have done represents actual work, whilst in this country we have practically no precedents in regard to electrical tramway practice.

The only paper read at the meeting was a contribution by Prof. Frederic W. Burstall; it embodied the first report of the Gas Engine Research Committee that had been appointed by the Institution, and of which Prof. Alexander Kennedy is the chairman. The object of the experiments described was to determine the effect produced on the economy of gas engines by altering one or more of the conditions which govern their working. The problem is one of a complex nature and presents considerable difficulties, especially as the gas engine has not like the steam engine been made the object of investigation by many authorities for a great number of years. The factors considered by the Cummittee were the amount of compression, the speed, the ratio of air to gas, and the amount of heat rejected through the walls of the cylinder. The engine used was of small size, perhaps too small to afford altogether satisfactory results; but the Committee were not to blame for this, for they had to work with such tools as they could command. The nominal power of the engine was 2 N.H.P., and the maximum that could be developed was 5 I.H.P; it was made by Messrs. Fielding and Platt, of Gloucester. The author stated that an increase of compression in a gas engine is often regarded as being conducive to more economical results, but it is uncertain whether the increase in economy is really due to the compression alone. It is, perhaps, fair to state that the Committee recognised that the absolute economy of the engine tried-which was specially constructed for experimental purposes-would be inferior to the economy that could be obtained by a larger motor; still, it was concluded that the comparative economies under different conditions would not be different in the two sizes; moreover, it was stated that it would have been impossible to measure with precision certain quantities, such as the volume of air, had the engine been larger. The compression employed in the expertments varied between $35 \mathrm{lbs}$. and $90 \mathrm{lbs}$. per square inch. The observations taken included measurements of the gas and of the air supplies, measurement of heat rejected into the jacket, sampling of exhaust gases, and determination of the I.H.P. developed. Seventeen tests were taken, and the mechanical efficiency of the engine was found to vary from 76 to 84 per cent., the mean value of the whole seventeen tests being 81 per cent. On a full power test the engine was running at 197 revolutions per minute, the compression per square inch absolute was I03 lbs., the ratio of clearance to cylinder volume was 0.25 , and the ratio of explosions to the maximum possible was 92 per cent. Under these circumstances the 